\title{
People's Concerns With the Prediction of COVID-19 in Bangladesh: Application of Autoregressive Integrated Moving Average Model
}

\author{
Md. Ismail Hossain ${ }^{\circledR}$, Ahmed Abdus Saleh Saleheen $^{1}$, Iqramul Haq ${ }^{2 *}$, Maliha Afroj Zinnia $^{3}{ }^{\circledR}$, Md. Rifat $^{2}$
} Hasan $^{1}{ }^{\circledR}$, Samia Kabir ${ }^{\circledR}$, Md. Injamul Haq Methun ${ }^{\circledR}{ }^{\oplus}$, Md. Iqbal Hossain Nayan $^{5}$, Ashis Talukder ${ }^{\circledR}$

'Department of Statistics, Jagannath University, Dhaka-1100, Bangladesh

${ }^{2}$ Department of Agricultural Statistics, Sher-e-Bangla Agricultural University, Dhaka-1207, Bangladesh

${ }^{3}$ Department of Pharmacy, East West University, Dhaka-1212, Bangladesh

${ }^{4}$ Statistics Discipline, Tejgaon College, Dhaka-1215, Bangladesh

${ }^{5}$ Research \& Development Department, Orion Pharma Ltd, Bangladesh

${ }^{6}$ Statistics Discipline, Khulna University, Khulna 9208, Bangladesh

Corresponding Author: Iqramul Haq, MSc, Department of Agricultural Statistics, Sher-e-Bangla Agricultural

University, Dhaka-1207, Bangladesh. Tel: +880-1715331220, Email: iqramul.haq@sau.edu.bd

Received February 8, 2021; Accepted April 19, 2021; Online Published May 7, 202

\begin{abstract}
Introduction: The coronavirus disease 2019 (COVID-19) has become a public health concern, and behavioral adjustments will minimize its spread worldwide by $80 \%$. The main purpose of this research was to examine the factors associated with concerns about COVID-19 and the future direction of the COVID-19 scenario of Bangladesh.

Methods: The binary logistic regression model was performed to assess the impact of COVID-19 concern in Bangladesh. Based on data obtained through online surveys in November 2020 and to predict the next 40 days daily confirmed and deaths of COVID-19 in Bangladesh by applying the Autoregressive Integrated Moving Average (ARIMA) model.

Results: The study enrolled 400 respondents, with 253 (63.2\%) were male, and 147 (36.8\%) were female. The mean age of respondents was $25.13 \pm 5.74$ years old. Almost $70 \%$ of them were found to be concerned about the COVID-19 pandemic. The result showed that respondents' education level, knowledge regarding COVID-19 transmits, households with aged people, seasonal flu and HD/respiratory problems, and materials used while sneezing/coughing significantly influenced COVID-19 concerns. The analysis predicted that confirmed cases would gradually decrease for the ARIMA model while death cases will be constant for the next 40 days in Bangladesh.

Conclusion: The current study suggested that knowledge about COVID-19 spread and education played a vital role in the decline of COVID-19 concerned. A particular program should focus on creating an awareness of the disadvantages of concerns about the COVID-19 pandemic by augmenting knowledge about COVID-19 spread, enhancing Education in Bangladesh.

Keywords: COVID-19, MERS-CoV, SARS, Quarantine, Education, Health
\end{abstract}

Citation: Hossain MI, Saleheen AAS, Haq I, Zinnia MA, Hasan MR, Kabir S, et al. People's concerns with the prediction of COVID-19 in Bangladesh Application of autoregressive integrated moving average model. Int J Travel Med Glob Health. 2021;9(2):84-93. doi:10.34172/ijtmgh.2021.14.

\section{Introduction}

After the emergence of severe acute respiratory syndrome (SARS) and Middle East respiratory syndrome-related coronavirus (MERS-CoV), a new form of coronavirus appeared in December 2019. This coronavirus resulted in an epidemic based in Wuhan, China, causing more than 118000 cases and 4291 deaths in 114 countries in just three months, which guided the World Health Organization (WHO) on March 11, 2020, to declare it a global pandemic. ${ }^{1-5}$ This novel coronavirus originally caused coronavirus disease 2019
(COVID-19), but subsequently, on February 11, 2020, the International Committee on Virus Taxonomy announced this new coronavirus severe acute respiratory syndrome coronavirus 2 (SARS-CoV-2). ${ }^{6-8}$

The COVID-19 also spread in more than 213 countries and territories, with 72471883 confirmed cases accompanied by 1616835 death cases till December 13,2020'. This pandemic led to a major global public health campaign to stop the spread of COVID-19 by taking certain steps, such as washing hands, avoiding touching face, wearing masks in public places, and

Copyright $\odot 2021$ The Author(s). This is an open-access article distributed under the terms of the Creative Commons Attribution License (http:// creativecommons.org/licenses/by/4.0), which permits unrestricted use, distribution, and reproduction in any medium, provided the original work is properly cited. 
maintaining a physical distance. ${ }^{10}$ This highly contagious virus conducted a great number of infections, causing an overload of the health care systems and lockdowns in so many countries, disrupting everyday life. ${ }^{11-14}$

The SARS-CoV-2 mortality rate varies significantly. The authentic death toll was expected to be higher than confirmed cases as there were limitations in testing and issues in the attribution of the cause of the death. For reporting death, countries were asked to abide by a standard, that is, "cause of death' classification introduced by the WHO's Classification of Diseases guidelines. ${ }^{15-18}$

As of December 13, 2020, according to the Institute of Epidemiology, Disease Control \& Research (IEDCR), there were 490533 confirmed COVID-19 cases, including a total of 5348 related deaths in Bangladesh, where the case fatality rate was $1.44 \% .{ }^{19}$ The Ministry of Health and Family Welfare and Directorate General of Health Services (DGHS) divided different areas as red, yellow and green zone based on the prevailing risk of the spreading of COVID-19. ${ }^{20}$

Bangladesh is one of the most densely populated developing country and having extreme inadequacy of testing assays raised concern as this may lead to many undetected cases. ${ }^{21}$

The healthcare systems in numerous countries were pushed to a breaking point. Still, there was no estimation that how long this situation will exist, how many individuals will be infected, and how long normal life will be disrupted. Such unpredictable consequences and uncertainty, and misinformation about the disease influenced people's mental health and caused traumatic stress. ${ }^{22}$

Although the COVID-19 cases are declining in Bangladesh, the rate is not that satisfactory and, the prediction of future movement is crucial. Therefore, based on the online survey, the primary purpose of this study was to explore the current profile of people's concerns about COVID-19 and factors associated with the COVID-19 concern among people in Bangladesh and forecast the future incidence of COVID-19, which was essential. Our study also enlightened some useful recommendations for the authorities to take the necessary strategies to fight and diminish the COVID-19 spread.

\section{Methods \\ Study Setting}

This study is a cross-sectional study and based on both primary data and secondary data. In terms of primary data, data was conducted through an online-based questionnaire survey collected from November 15, 2020, to November 25,2020 . A semi-structured questionnaire was developed in google form to gather relevant information regarding COVID-19. The questionnaire was designed to three sections: consent section, socio-demographic question, and question on the relevant information regarding COVID-19 in the last section. In addition to secondary data, The COVID-19 data from IEDCR was used as secondary data to predict the future scenario of the COVID-19 pandemic. ${ }^{19}$ They provided daily data consisting of bar graphs representing confirmed cases, deaths, active cases, and recovered cases. From these data, we included only the confirmed and death cases in our study.

\section{Study Population}

After developing the questionnaire, the respondents were adults who use Facebook and understood questions in English. We sent the link through Facebook Messenger only to fill out the form. Therefore, adults who use Facebook and understood questions in English were the study population in this current analysis.

\section{Exclusion and Inclusion Criteria}

Respondents under the age of 18 and who did not have any Facebook account were excluded from the survey rather, only respondents aged 18 or older who had a Facebook account were considered for this study.

\section{Participants and Sampling}

The data is based on a convenient sampling technique to draw a sample of respondents in this analysis. Based on convenient sampling, a total of 400 respondents aged 18 years or more were considered and answered voluntarily, and the desired information from them was carefully assembled. Therefore, the total sample in this study was 400 adults who were used Facebook in this analysis.

\section{Dependent Variable}

People's concern about COVID-19 was assessed as the current dependent variable in this analysis. Here we recode, $1=$ Concerned about COVID-19 and $0=$ Not concerned about COVID-19.

\section{Independent Variables}

In this current research, the employed independent variables were educational status, knowledge about COVID-19 spreading mechanism and symptoms, the infected local/ adjacent area, the occurrence of seasonal flu among family members, cleaning hand regularly, having family member over 50 years old, heart disease/respiratory problem in the family, regular outgoing, being free from germs, using masks, covering face while sneezing, and proper knowledge about how vitamin $\mathrm{C}$ boosts immunity.

\section{Statistical Methods}

Simple descriptive analysis and multivariate statistical analyses were performed in this analysis. Descriptive statistics were used for frequency, and percent of age distributions were analyzed for all variables.

Binary logistic regression was used to assess the effect of an independent variable on concerns about COVID-19 in Bangladesh.

Let $Y_{i}$ denote the binary dependent variable for the $i^{\text {th }}$ observation.

Where, $Y_{i}=\left\{\begin{array}{l}1, \text { if the Respondent is concerned about COVID }-19 \\ 0, \text { if the Respondent is not concerned about COVID - }\end{array}\right.$

$X_{i 1}, \ldots, X_{i p}$ is a set of explanatory variables, which can be quantitative or indicator variables referring to the level of categorical variables.

Since $Y$ is a binary variable, it has a Bernoulli distribution 
with parameter $\pi_{i}$ The dependence of the probability of success on independent variables was assumed to be respectively as:

$P\left(Y_{i}=1\right)=\pi_{i}=\frac{\exp \left(\beta_{0}+\beta_{1} X_{i 1}+\ldots+\beta_{p} X_{i p}\right)}{1+\exp (\beta+\beta X+\ldots)}$

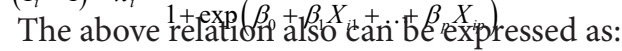

$g(X)=\operatorname{logit}\left(\pi_{i}\right)=\log \frac{\pi_{i}}{1-\pi_{i}}=\beta_{0}+\beta_{1} X_{i 1}+\ldots+\beta_{p} X_{i p}$

The likelihood was maximized by finding estimates of the most likely parameters to give us the data. The maximum likelihood estimator of $\beta_{0}$ and $\beta_{1}$ can be obtained by maximizing:

$L\left(\beta_{0}, \beta_{1}\right)=\prod_{i=1}^{n} \frac{\exp \left\{Y_{i}\left(\beta_{0}+\beta_{1} X_{i}\right)\right\}}{1+\exp \left(\beta_{0}+\beta_{1} X_{i}\right)}$

For future prediction, a well-known statistical forecasting model named Autoregressive Integrated Moving Average (ARIMA) model was used, developed by Box. ${ }^{23}$

The SPSS version 25 software (IBM, Corporation, Armonk, NY, USA) was applied for data processing. The R Project for Statistical Computing version 3.6.0 (R Core Team-2019) was used to perform the statistical analyses.

\section{Results}

Among 400 respondents, 253 were male, and 147 were female in the study. The mean age of the respondents was 25.13 years, and the standard deviation was 5.74 years. In the present

study, Cronbach's alpha was 0.713 . In the following sections, the results were shown by analyzing the data of these 400 respondents.

\section{Percentage Distribution of Various Factors}

Table 1 illustrates the frequency distribution of sociodemographic factors and health-related general knowledge among Bangladeshi residents. Table 1 shows that the proportion of variables was higher among the respondents who had higher secondary and above education (95\%), who knew that the novel coronavirus is transmitted by sneezing and coughing (47.5\%) and who could recognize the symptoms of COVID-19 (95\%). Moreover, as per Table 1, the respondents whose family members were not infected with seasonal flu (84\%), who washed their hands regularly (98.8\%), who had no heart disease patients, and elderly members $(>50$ years old) in their family had a higher proportion of variables. Based on information delivered by the respondents, almost $60 \%(59.8 \%)$ of families refrained from going outside, and $94.8 \%$ of participants sanitized themselves after coming from outside. Accordingly, the respondents stick to the practice of using some materials when they feel coughing or sneezing. To be specific, the majority of the respondents ( $81 \%)$ used tissues or handkerchiefs, alongside $16 \%$ who covered their mouth with their hand while coughing or sneezing. The table also revealed that more than $80 \%$ of the respondents believed that vitamin C helps prevent the novel coronavirus. Also, over $73 \%$ (73.8\%) were concerned about COVID-19, while $26.3 \%$ were not concerned at all.

\section{Percentage Distribution of Multiple Responses}

The frequency distribution of respondents and government actions/steps taken for COVID-19 was exhibited in Table 2. Only the two steps taken by the government were not to

Table 1. \% Distribution of the People's Socio-Demographic Factors and HealthRelated General Knowledge in Bangladesh

\begin{tabular}{|c|c|c|}
\hline Variables & Number & Percent \\
\hline \multicolumn{3}{|l|}{ Educational status } \\
\hline Secondary education & 20 & 5.0 \\
\hline Higher secondary and above & 380 & 95.0 \\
\hline \multicolumn{3}{|l|}{ Knowledge of COVID-19 spread } \\
\hline Touching infected people/object & 100 & 25 \\
\hline Sneezing/coughing from infected people & 190 & 47.5 \\
\hline Droplets from infected people & 56 & 14 \\
\hline Others & 54 & 13.5 \\
\hline \multicolumn{3}{|l|}{ Knowledge about Symptoms } \\
\hline Yes & 380 & 95 \\
\hline No & 20 & 5 \\
\hline \multicolumn{3}{|l|}{ Infected local/adjacent area } \\
\hline Yes & 210 & 52.5 \\
\hline No & 102 & 25.5 \\
\hline Do not know & 88 & 22.5 \\
\hline \multicolumn{3}{|l|}{ Seasonal flu in family } \\
\hline Yes & 64 & 16.0 \\
\hline No & 336 & 84.0 \\
\hline \multicolumn{3}{|l|}{ Clean hand regularly } \\
\hline Yes & 395 & 98.8 \\
\hline No & 5 & 1.3 \\
\hline \multicolumn{3}{|l|}{$50+$ aged people in the family } \\
\hline Yes & 305 & 76.3 \\
\hline No & 95 & 23.8 \\
\hline \multicolumn{3}{|l|}{ HD/Respiratory problem in the family } \\
\hline Yes & 156 & 39 \\
\hline No & 244 & 61 \\
\hline \multicolumn{3}{|l|}{ Regular outgoing } \\
\hline Yes & 161 & 40.3 \\
\hline No & 239 & 59.8 \\
\hline \multicolumn{3}{|l|}{ Free from germs } \\
\hline Yes & 379 & 94.8 \\
\hline No & 21 & 5.3 \\
\hline \multicolumn{3}{|l|}{ Use materials when feel cough, sneezing } \\
\hline The face should be covered with tissue/handkerchief & 324 & 81.0 \\
\hline The face should be covered with hands & 64 & 16.0 \\
\hline Others & 12 & 3.0 \\
\hline \multicolumn{3}{|l|}{ Vitamin C is helpful for COVID-19 } \\
\hline Yes & 329 & 82.3 \\
\hline No & 71 & 17.8 \\
\hline \multicolumn{3}{|l|}{ Concerned about COVID-19 } \\
\hline Yes & 295 & 73.8 \\
\hline No & 105 & 26.3 \\
\hline
\end{tabular}


Table 2.\% Distribution of Respondent and Government Actions/Steps Taken for COVID-19 in Bangladesh

\begin{tabular}{|c|c|c|}
\hline Variables & Number & Percent \\
\hline \multicolumn{3}{|l|}{ The government took steps } \\
\hline Do not move out of the room without an urgent need & 275 & 68.8 \\
\hline Use masks and gloves when needed & 228 & 57.0 \\
\hline Avoid mass transit and public meetings & 45 & 11.2 \\
\hline Maintain social distances & 149 & 37.2 \\
\hline $\begin{array}{l}\text { 14-day compulsory home quarantine for people with } \\
\text { sneezing cough and non-compliance }\end{array}$ & 29 & 7.2 \\
\hline Restricting traffic in religious places of worship & 45 & 11.2 \\
\hline Others & 158 & 39.5 \\
\hline \multicolumn{3}{|l|}{ Foods taken by the respondents } \\
\hline $\begin{array}{l}\text { Fruits (lemon, orange, grape, grapefruit, tomato, taco } \\
\text { fruit) }\end{array}$ & 269 & 92.7 \\
\hline Vegetables (raw pepper, red pepper, papaya) & 82 & 28.3 \\
\hline Ceevit/another Vitamin C tablet & 55 & 19.0 \\
\hline Others & 9 & 3.1 \\
\hline \multicolumn{3}{|l|}{ Family actions are taken for COVID-19 } \\
\hline Making everyone aware of the spreading of the virus & 55 & 13.8 \\
\hline $\begin{array}{l}\text { Keeping in mind that everyone is washing hands } \\
\text { regularly }\end{array}$ & 159 & 39.8 \\
\hline Preventing members from going out without any need & 181 & 45.2 \\
\hline $\begin{array}{l}\text { Regular cleaning and spraying disinfectants around } \\
\text { the home }\end{array}$ & 220 & 55.0 \\
\hline Others & 122 & 30.5 \\
\hline \multicolumn{3}{|l|}{ The respondent took several steps } \\
\hline Creating social distancing & 229 & 57.2 \\
\hline Washing hands frequently & 193 & 48.2 \\
\hline Self-cleaning and also cleaning the surroundings & 117 & 29.2 \\
\hline Not to touch the nose, face, and eyes with hands & 46 & 11.5 \\
\hline Not to move out of the room without any need & 122 & 30.5 \\
\hline Wearing masks and gloves when leaving the room & 122 & 30.5 \\
\hline Others & 150 & 37.5 \\
\hline \multicolumn{3}{|l|}{ Knowledge of COVID-19 symptoms } \\
\hline Acute fever & 346 & 91.1 \\
\hline Seasonal flu/common cold/dried cough & 329 & 86.6 \\
\hline Respiratory problems & 217 & 57.1 \\
\hline Pneumonia/pneumonia like symptoms & 13 & 3.4 \\
\hline Disability & 2 & 0.5 \\
\hline Sore throat & 189 & 49.7 \\
\hline Others & 142 & 37.4 \\
\hline
\end{tabular}

move out of the house without any urgent need (68.8\%) and to use masks and gloves when needed (57 \%) and, these were recorded by more than $50 \%$ of the respondents in the sense of preserving social distance $(37.2 \%)$. Avoiding mass transits and public meetings were also mentioned by some respondents, along with restricting traffic in religious places. Besides, it was revealed by a large number of respondents that they took fruits (92.7\%), vegetables (28.3\%), Ceevit/ other vitamin C tablets (19\%), and other things (3.1\%) as a source of vitamin $\mathrm{C}$. More than half of the respondents mentioned that they embraced regular cleaning and spraying disinfectants around the home (55\%) as family safety actions. Maintaining social distances $(57.2 \%)$ was taken as personal safety. The respondents' additional family safety actions were preventing members from going out without any need (45.2\%) and keeping in mind that everyone is washing hands regularly $(39.8 \%)$. Moreover, it was also shown from Table 2 and respondents possessed outstanding knowledge of COVID-19 symptoms and, according to them, the symptoms were acute fever $(91.1 \%)$, seasonal flu/common cold/dried cough $(86.6 \%)$ and, respiratory problems $(57.1 \%)$.

\section{Collinearity Diagnostic of Background Variables}

Table 3 showed whether or not the independent variables corresponded. Whenever two or more independent variables were correlated in the regression model, multicollinearity occurs, this can be identified using the tolerance and its reciprocal called the variance inflation factor (VIF)..$^{24,25}$ Multicollinearity can be used to show how much the variance of the coefficient estimate is inflated by the VIF. Usually, typical suggestions for a cutoff point are 5 or 10 , as there was no conventional cutoff value or method that prescribes multicollinearity when a VIF was too large. ${ }^{24}$ The VIF value of each variable in this study was below 2 .

In this instance of tolerance, to determine multicollinearity, no formal cutoff value could be used with tolerance. ${ }^{26}$ Manifested by Myers, tolerance value under 0.1 expresses serious collinearity complications, whereas Menard suggested a tolerance value not more than 0.2 exhibits a potential collinearity problem. ${ }^{27,28}$ Based on experiments, tolerance, which is 0.1 or less, is a cause of concern. ${ }^{26}$ All the variables of the current study with tolerance values were larger than 0.1 .

From the above review, this was remarked that multicollinearity was not present in this study.

\section{Multivariate Analysis of COVID-19 Concernedness}

The result of the binary logistic regression to show the effect of COVID-19 concernedness on the background variables is shown in Table 4. The Respondent's educational status was one of the determining factors for COVID-19 concerned. As

Table 3. Collinearity diagnostics among the independent variables

\begin{tabular}{lcc}
\hline \multirow{2}{*}{ Associated Factors } & \multicolumn{2}{c}{ Collinearity Statistics } \\
\cline { 2 - 3 } & Tolerance & VIF \\
\hline Educational status & 0.933 & 1.072 \\
Knowledge of COVID-19 spread & 0.924 & 1.082 \\
Knowledge about symptoms & 0.906 & 1.104 \\
Infected local/adjacent area & 0.955 & 1.048 \\
Seasonal flu in family & 0.962 & 1.039 \\
Clean hand regularly & 0.946 & 1.057 \\
50+ aged people in the family & 0.838 & 1.194 \\
HD/Respiratory problem in family & 0.885 & 1.130 \\
Regular outgoing & 0.962 & 1.039 \\
Free from germs & 0.953 & 1.050 \\
\hline Use materials when feel cough, sneezing & 0.965 & 1.036 \\
Vitamin C is helpful for COVID-19 & 0.953 & 1.049 \\
\hline
\end{tabular}


Table 4. Binary Logistic Regression for Analysis of People's Concern on COVID-19 and Socio-demographic Factors in Bangladesh

\begin{tabular}{|c|c|c|c|}
\hline Associated Factors & OR & $95 \% \mathrm{Cl}$ & $P$ Value \\
\hline \multicolumn{4}{|l|}{ Educational status } \\
\hline Secondary education (ref.) & 1 & & \\
\hline Higher secondary and above & $0.28^{*}$ & $0.09-0.83$ & 0.02 \\
\hline \multicolumn{4}{|l|}{ Knowledge of COVID-19 spread } \\
\hline Touching infected people/object (ref.) & 1 & & \\
\hline Sneezing/coughing from infected people & $0.42^{* *}$ & $0.23-0.76$ & 0.004 \\
\hline Droplets from infected people & $0.40^{*}$ & $0.17-0.92$ & 0.03 \\
\hline Others & $0.38^{*}$ & $0.16-0.84$ & 0.02 \\
\hline \multicolumn{4}{|l|}{ Knowledge about symptoms } \\
\hline Yes (ref.) & 1 & & \\
\hline No & 0.38 & $0.07-1.40$ & 0.1 \\
\hline \multicolumn{4}{|l|}{ Infected local/adjacent area } \\
\hline Yes (ref.) & 1 & & \\
\hline No & 1.62 & $0.89-2.96$ & 0.11 \\
\hline Do not know & $2.41^{* *}$ & $1.32-4.41$ & 0.004 \\
\hline \multicolumn{4}{|l|}{ Seasonal flu in family } \\
\hline Yes (ref.) & 1 & & \\
\hline No & $2.2^{7 *}$ & $1.09-5.14$ & 0.04 \\
\hline \multicolumn{4}{|l|}{ Clean hand regularly } \\
\hline Yes (ref.) & 1 & & \\
\hline No & 0.37 & $0.01-7.76$ & 0.60 \\
\hline \multicolumn{4}{|l|}{$50+$ aged people in the family } \\
\hline Yes (ref.) & 1 & & \\
\hline No & $0.40^{* *}$ & $0.20-0.76$ & 0.006 \\
\hline \multicolumn{4}{|l|}{ HD/Respiratory problem in family } \\
\hline Yes (ref.) & 1 & & \\
\hline No & $2.12^{* *}$ & $1.23-3.73$ & 0.008 \\
\hline \multicolumn{4}{|l|}{ Regular outgoing } \\
\hline Yes (ref.) & 1 & & \\
\hline No & 1.24 & $0.76-2.05$ & 0.39 \\
\hline \multicolumn{4}{|l|}{ Free from germs } \\
\hline Yes (ref.) & 1 & & \\
\hline No & 1.18 & $0.33-3.60$ & 0.78 \\
\hline \multicolumn{4}{|l|}{ Use materials when feel cough, sneezing } \\
\hline $\begin{array}{l}\text { The face should be covered with tissue/ } \\
\text { handkerchief (ref.) }\end{array}$ & 1 & & \\
\hline The face should be covered with hands & 1.45 & $0.74-2.77$ & 0.26 \\
\hline Others & $3.94^{*}$ & $1.06-14.51$ & 0.03 \\
\hline \multicolumn{4}{|l|}{ Vitamin C is helpful for COVID-19 } \\
\hline Yes (ref.) & 1 & & \\
\hline No & 1.40 & $0.76-2.54$ & 0.27 \\
\hline
\end{tabular}

Note: significant at ${ }^{* *} P<0.01$ and ${ }^{*} P<0.05$, ref. $=$ Reference Category.

the table showed, in this COVID-19 pandemic, 72\% (odds ratio $[\mathrm{OR}]=0.28$, CI: $0.09-0.83, P$ value $=0.02$ ) of those with higher secondary and higher education levels were less likely to be concerned than those with secondary education levels.

There was also a notable association between COVID-19 and participants who knew how COVID-19 spread ( $P$ value
$<0.05)$. Of all participants, those who knew that COVID-19 spreads through sneezing/coughing were $58 \% \mathrm{OR}=0.42$, CI: $0.23-0.76, P$ value $=0.004$ ) less likely to be concerned than who knew that it spreads only by touching infected people/ object. Droplets from infected people, with $60 \%(\mathrm{OR}=0.40$, CI: $0.17-0.92, P$ value $=0.03$, were less likely to be concerned than those who knew it spreads only by touching infected people/objects.

Moreover, the present study showed that those unaware of whether there were infected persons in their area/adjacent were 2.4 times $(\mathrm{OR}=2.41, \mathrm{CI}$ : 1.32-4.41, $P$ value $=0.004)$ more concerned than the others. Seasonal influenza in family members also showed significant effects in terms of concern about COVID-19. Surprisingly, our study found that respondents without seasonal influenza in the family were 2.27 times $(\mathrm{OR}=2.27, \mathrm{CI}: 1.09-5.14, P$ value $=0.04)$ more likely to be concerned than those who had seasonal influenza. Another impressive finding of our study was that families with elder members over 50 years of age were more concerned compared to their counterparts. Families who did not have heart disease or respiratory problems were 2.12 times (OR $=2.12$, CI: $1.23-3.73, P$ value $=0.008)$ more concerned than those who had these types of health problems.

There was statistical significance with the associated factors of using some materials when coughing, sneezing, and concerned respondents about COVID-19. Respondents who did not use tissues and hands when sneezing or coughing were 3.94 times $(\mathrm{OR}=3.94, \mathrm{CI}: 1.06-14.51, P$ value $=0.03)$ more concerned about COVID-19 than those who used tissues and hands when sneezing or coughing in a public place.

\section{Prediction Analysis of COVID-19}

Applied confirmed and death data series to fit two ARIMA

Table 5. Different ARIMA Model for a Confirmed Case

\begin{tabular}{lcc}
\hline Model & AIC & BIC \\
\hline ARIMA $(2,1,2)$ & 3516.52 & 3534.08 \\
ARIMA $(0,1,0)$ & 3537.02 & 3540.88 \\
ARIMA $(1,1,2)$ & 3514.02 & 3528.07 \\
*ARIMA $(1,1,4)$ & 3500.86 & 3521.93 \\
ARIMA $(1,1,5)$ & 3502.78 & 3527.37 \\
ARIMA $(2,1,3)$ & 3513.50 & 3534.58 \\
ARIMA $(2,1,5)$ & 3501.00 & 3529.12 \\
\hline * Best ARIMA model & &
\end{tabular}

Table 6. Different ARIMA Model for Death Cases

\begin{tabular}{lcc}
\hline Model & AIC & BIC \\
ARIMA $(2,1,2)$ & 1644.40 & 1661.97 \\
ARIMA $(0,1,0)$ & 1755.75 & 1759.26 \\
ARIMA $(1,1,0)$ & 1677.49 & 1684.52 \\
*ARIMA $(0,1,1)$ & 1640.53 & 1647.56 \\
ARIMA $(1,1,1)$ & 1641.39 & 1651.94 \\
ARIMA $(0,1,2)$ & 1641.45 & 1651.99 \\
ARIMA $(1,1,2)$ & 1642.52 & 1656.57 \\
\hline
\end{tabular}

* Best ARIMA model. 
models to predict the next 40 days for both confirmed and death cases in Bangladesh. Tables 5 and 6 showed the results of the different ARIMA models for the (time series) confirmed and death cases of COVID-19, respectively. The best model was selected based on the principle of Bayesian information criterion (BIC) and Akaike's information criterion (AIC). It was observed that ARIMA $(1,1,4)$ and ARIMA $(0,1,1)$ were in good agreement for the current values of confirmed cases and deaths, respectively.

The ACF correlogram of the residuals (Figure 1) from the ARIMA $(1,1,4)$ model showed that all autocorrelations, except for lags 7 and 14, were within bounds and had no seasonality effect on occurrence. Figure 2 showed that the predicted confirmed cases were gradually decreasing, which was good news for the people of Bangladesh. Figure 3 showed the ACF correlogram of the residuals from the ARIMA $(0,1,1)$ model and demonstrated that except lag 14, all autocorrelations were within the band level. Figure 4 predicted the future death cases from the perspective of Bangladesh, and soon we are going to get a constant death case.

\section{Graphical Illustration of COVID-19}

The IEDCR published district-by-district data on the total number of confirmed cases and deaths per day. ${ }^{19}$ The geographic map in Figure 5 was created using this accurate data. We created this spatial map using December 13, 2020 (for confirmed cases) and December 6, 2020 (for deaths).

Concerning the confirmed cases, we have divided the whole country into three zones, successively orange, green, and blue. The orange zones denoted the areas with a higher level of infection and were therefore called "risk zone". The map illustrated that Dhaka and Chattogram districts had comparatively higher infection rates (>10000) and were assigned to an orange zone. Green zones had relatively fewer COVID-19 cases (5001-10000) than the orange zones. It is also evident from the map that in green zones, Bogura and Sylhet districts had more COVID-19 infection cases than other districts, indicating that necessary measures should be taken in these zones to prevent the increasing infection rate. The blue zones had slightly fewer confirmed cases.

Figure 5 also showed that most of the COVID-19 deaths occurred in Dhaka Division in terms of deaths. In addition, Figure 6 showed a representation of those affected by the key factors regarding COVID-19 from Bangladesh's perspective. Education, knowledge about the spread of the virus, hand washing, staying at home, the elderly population, and people with heart diseases were considered important factors in this figure. These factors should be given special consideration in future decisions regarding COVID-19.

\section{Discussion}

As mentioned earlier, our study aimed to explore the current profile of COVID-19 concerns and predication of COVID-19 among the inhabitants of Bangladesh and give directions to the policymakers about what initiatives should be adopted.

There was a negative association between respondent education and COVID-19 concerns. As per this research, the level of education was a key factor influencing COVID-19 concern, and this particular result was comparable to the

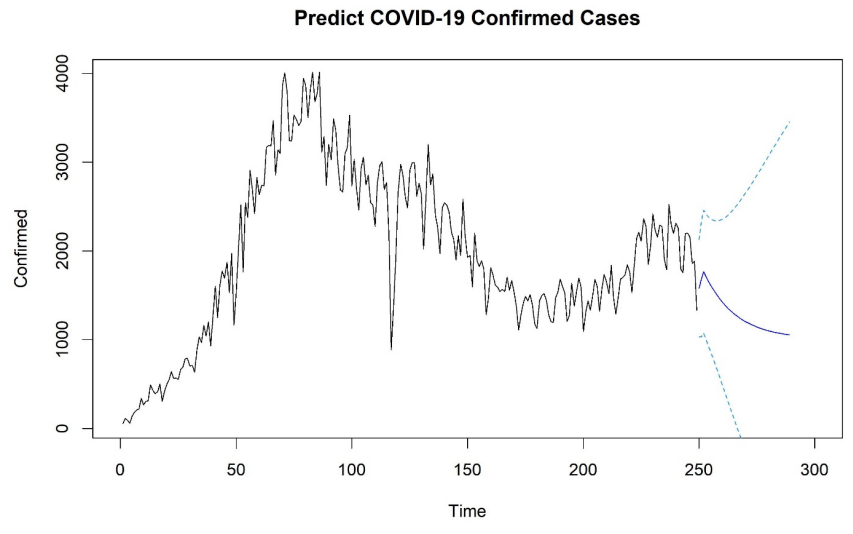

Figure 2. Predict COVID-19 Confirmed Cases.
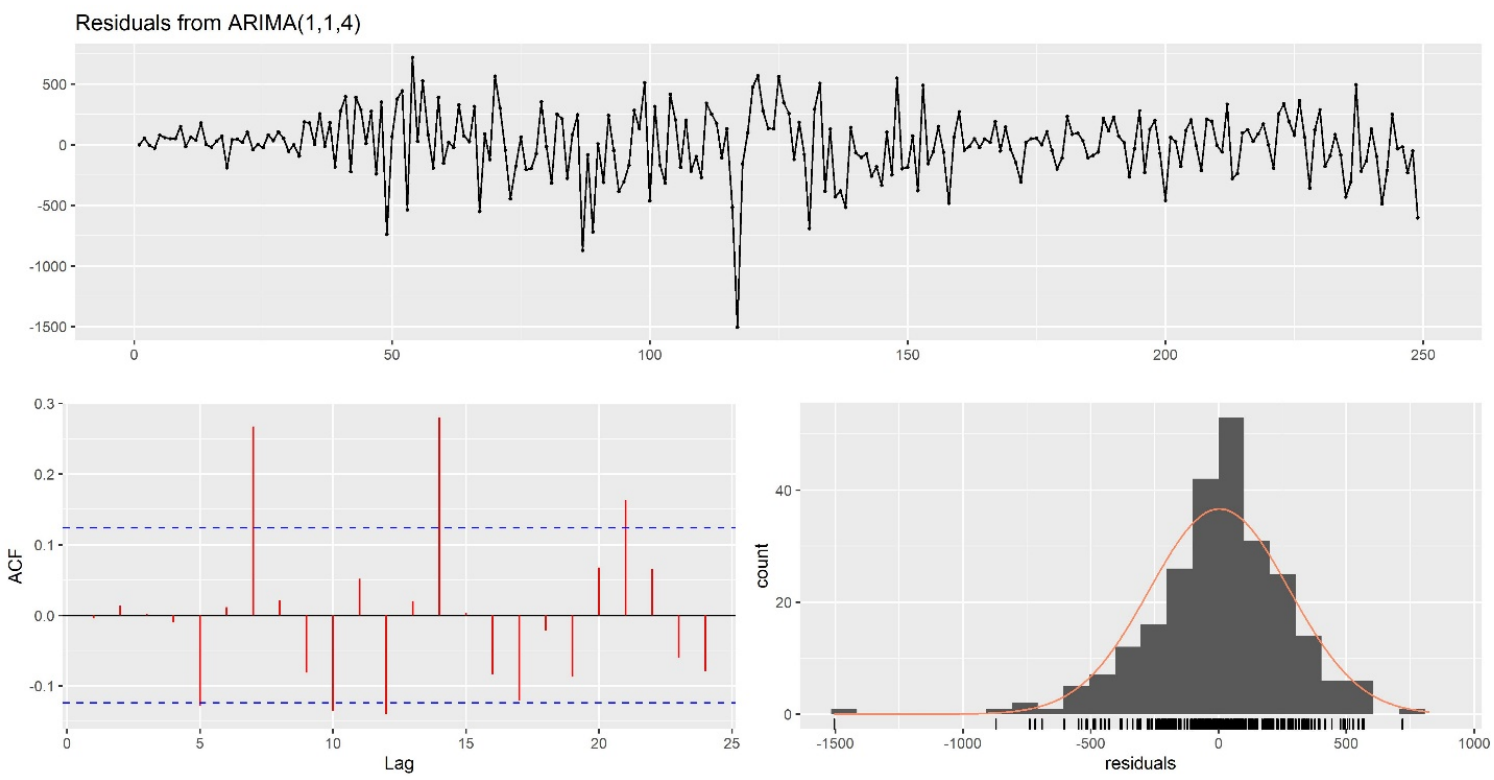

Figure 1. Residual Plots for ARIMA $(1,1,4)$ Model 

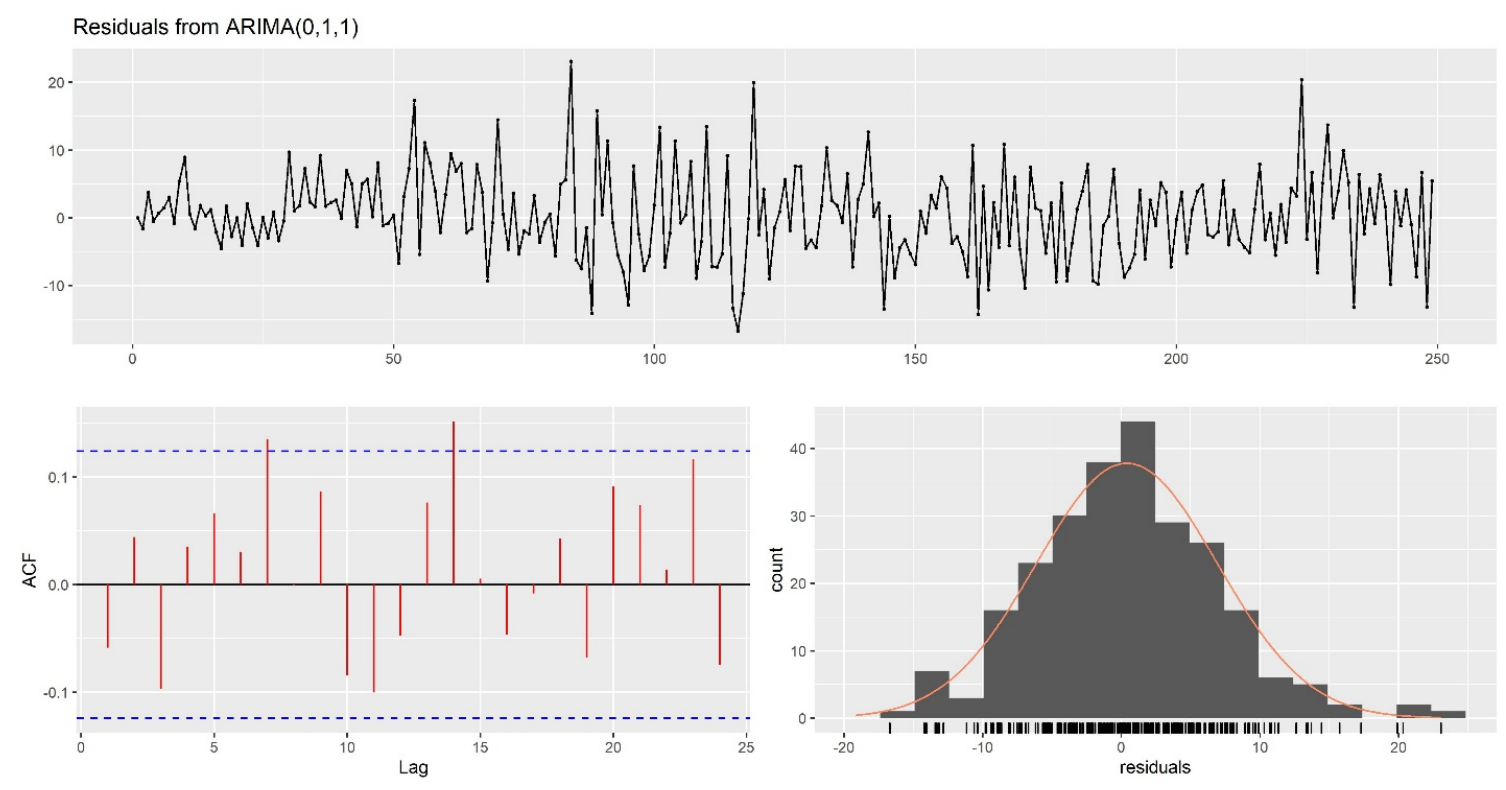

Figure 3. Residual Plots for $\operatorname{ARIMA}(0,1,1)$ Model.

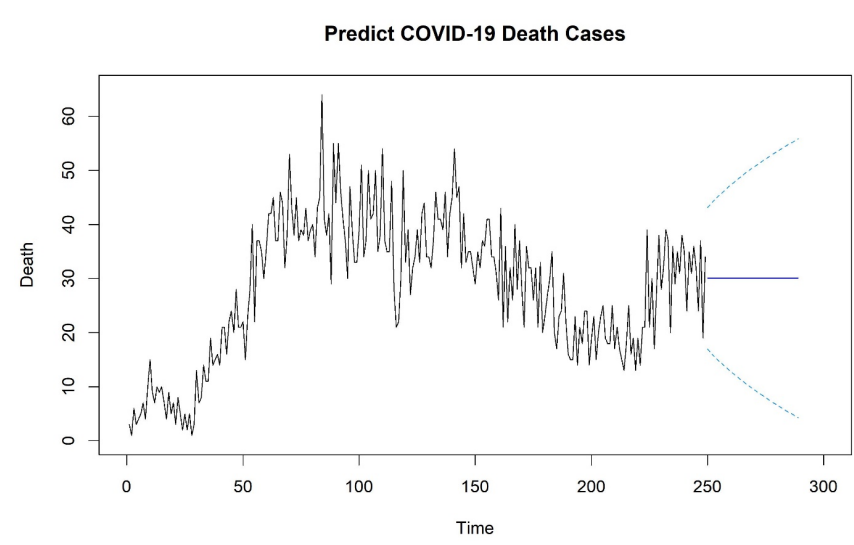

Figure 4. Predict COVID-19 Death Cases.

study carried out in India ${ }^{29}$ and Ethiopia. ${ }^{30}$ According to them, educational level is a known factor that influences disease awareness. The higher the level of education, the stronger the knowledge about diseases, and vice versa. The present analysis showed that higher secondary or above Education of Respondent had fewer concerns about the COVID-19 pandemic. Some other separate prior studies support this finding. ${ }^{29,31}$

Sneezing/coughing or droplets was significantly associated with COVID-19 concerns and spread. In Bangladesh, participants who were aware that COVID-19 spreads by sneezing/coughing or droplets were less concerned about the virus, although this was not coherent with the results of some other studies. ${ }^{32,33}$ Because in a populous country like Bangladesh, most people were poor and going outside the home for their livelihood. For that, people in Bangladesh have engaged in various work, gathering together for earning money in the cluster place. So that is one of the reasons why it was not consistent with previous research.

It was established from the study that respondents were more concerned about the virus in those areas where COVID-19 more occurred. In our analysis, those who were not conscious about whether there were infected people or not in their areas were more than two folds concerned than other individuals. An interesting finding of our analysis showed that those families having members infected with seasonal flu were less likely to be concerned than others. Besides, families with elderly persons over 50 years of age were more concerned, whereas having heart disease/respiratory problems in family members was less concerned about the virus. Also, from this study, individuals who did not go outside were comparatively more worried than others. Few studies demonstrated a direct interaction between going outside and the spreading of the virus responsible for COVID-19. ${ }^{34}$ Our study also indicated that $81 \%$ of respondents covered their faces when sneezing/ coughing with tissue/handkerchief/hands materials. There was in line with a survey conducted in Ethiopia. ${ }^{29}$ Moreover, people who covered their face with tissue/handkerchief/hand during sneezing/coughing to block droplets in a public place were less concerned than others, and this evidence coincides with other separate previous studies. ${ }^{33,35,36}$

If we notice carefully, the COVID-19 cases in Bangladesh seemed to be decreasing day by day. The prediction methods of the ARIMA model suggested the same findings and clearly showed that the number of daily cases in Bangladesh could decrease, and in case of death, it will be constant. However, another study conducted in Bangladesh ${ }^{37}$ found a somewhat contrary to our result. We described the results of the Residual plot from the ARIMA model, which showed non-seasonality impact on occurrence and prevalence, a similar conclusion reached by another researcher. ${ }^{38}$

This study showed a few limitations. Firstly, due to the insufficiency of funds, samples could not be collected to represent the whole of Bangladesh. Secondly, due to the sampling frame or list of the target population is not known, we had to consider a convenient sampling technique to draw a sample of respondents in this analysis. Thirdly, it was not feasible to discuss a comparatively great number of points. Fourthly, the cross-sectional nature of the study did not 

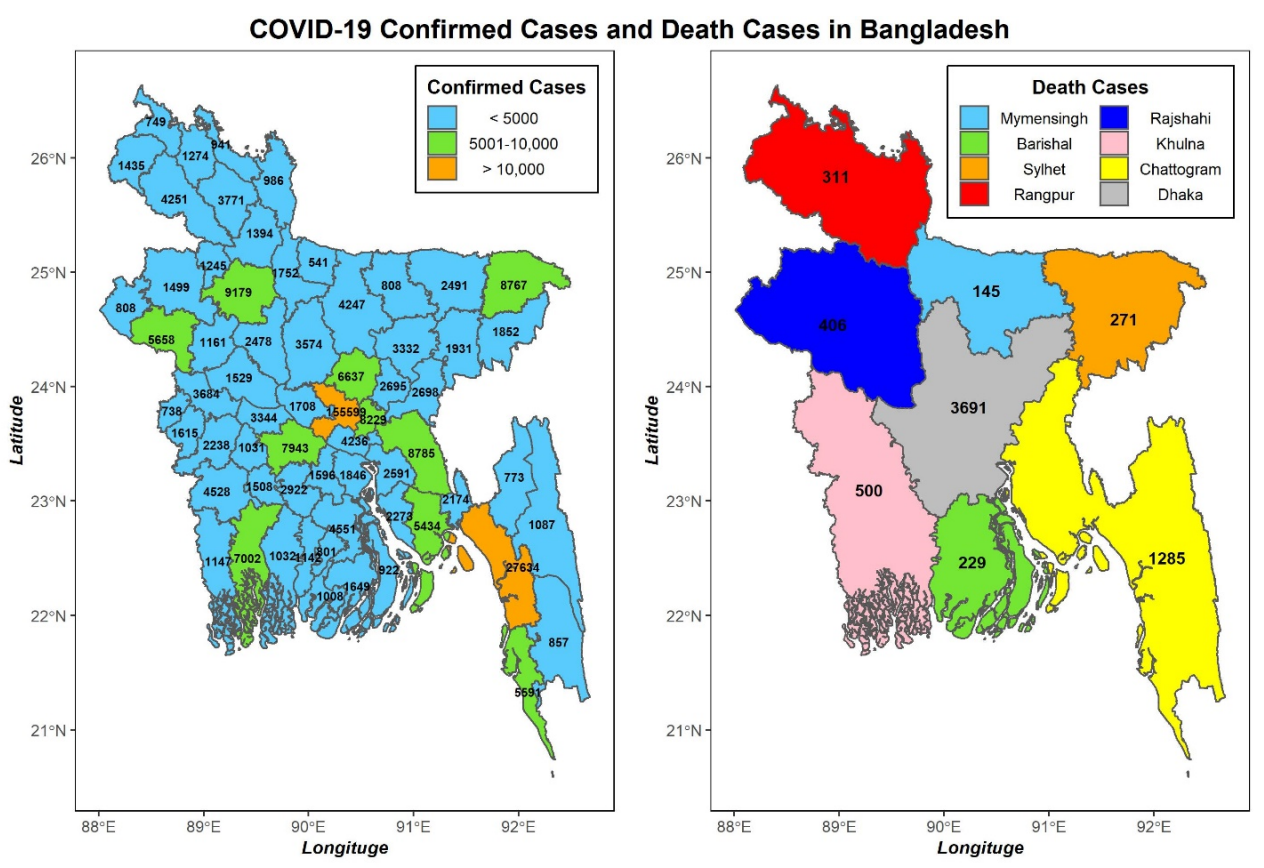

Figure 5. COVID-19 Situation in Bangladesh (Data source: IEDCR, 2020).

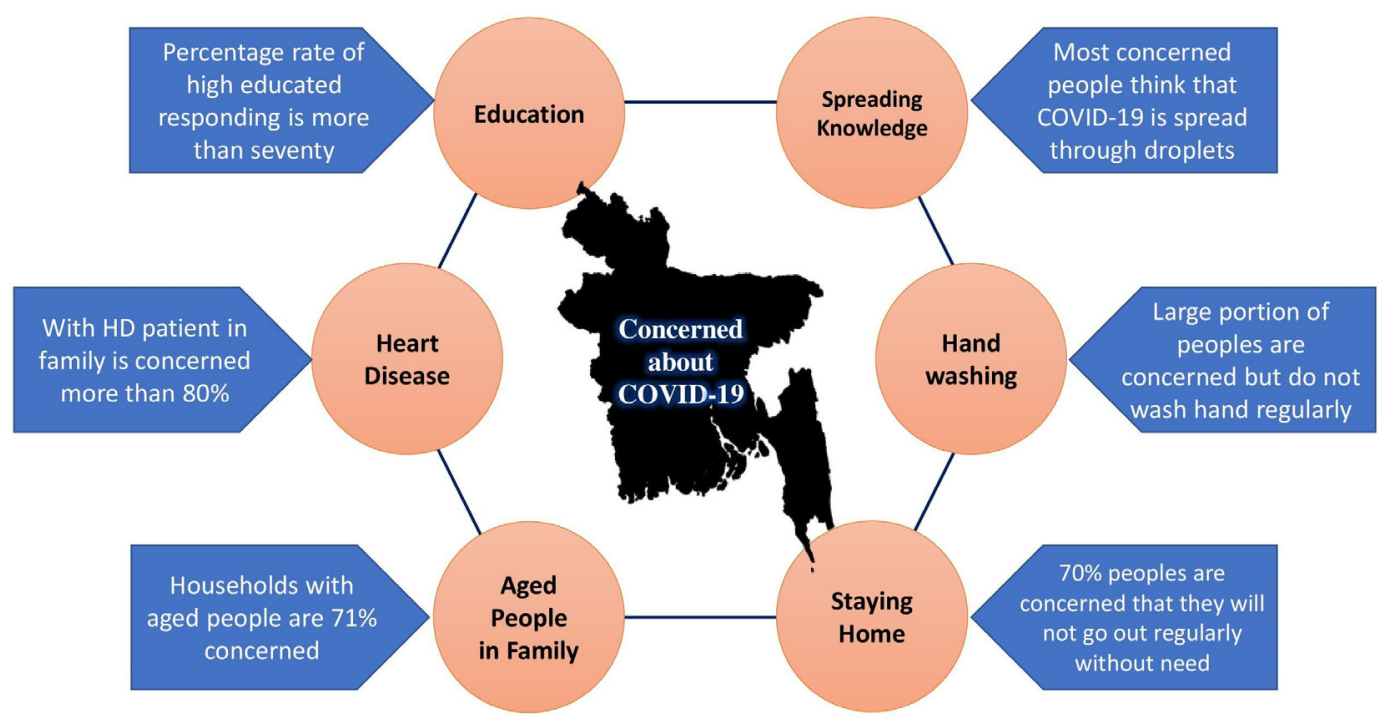

Figure 6. An Illustration of Concerned People With the Key Factors to COVID-19 From the Perspective of Bangladesh.

permit us to exhibit the relationship. Despite having such limitations, the study's objective was to analyze the behavior in massive COVID-19 outbreaks. Hence to throw some light to guide the responsible ones about how to manage pandemic, where necessary initiatives should be taken as well as where it is required to be

\section{Conclusion}

In summary, we conclude that educational status, knowledge about COVID-19 spread, infected local/adjacent area, seasonal flu in the family, 50 or more aged people in the family, $\mathrm{HD} /$ Respiratory problem in the family, use materials when feeling cough, sneezing were the most significant findings. In terms of the ARIMA predictive model, we revealed that confirmed cases gradually decreased in Bangladesh while death cases will be constant in Bangladesh. The World Health Organization (WHO) recommended wearing a mask, washing hands by handwash/hand sanitizer/soap for 20 minutes, and maintaining a social distance by lockdown was a way to prevent coronavirus and directly related to people's attitudes and their concern. In conformity with the study, it was evident that the COVID-19 situation in Bangladesh was very delicate. The Respondent's educational status was one of the determining factors for reduce COVID-19 concerns. Therefore, the awareness of respondents should be uplifted immediately. For this reason, to get rid of this predicament, the government should take different steps to reduce the COVID-19 spread. Concern by ensuring people awareness, knowledge, and unconcerned of this pandemic again execute the law for people to remove all types of gathering, mandatory 
Research Highlights

\section{What Is Already Known?}

The study revealed several factors associated with COVID-19 concerns among people in Bangladesh. Those family had fifty or more aged people were more concerned about COVID-19 pandemic in Bangladesh. In contrast, high education status is associated with lower levels of concern about COVID-19 among Bangladeshi people.

\section{What Does This Study Add?}

The present study identified people concerned about COVID-19 and the prediction of COVID-19 in the next 40 days in Bangladesh. In Bangladesh, participants aware that COVID-19 spreads by sneezing/coughing or droplets were less concerned about the virus. Those families' members who had heart disease or respiratory problems and seasonal flu were less concerned than members with no heart disease or respiratory problems. We believe that this study will be of significant interest for the policymaker to assess the current profile of COVID-19 and the future scenario of COVID-19 direction in Bangladesh.

wearing mask outside the home, and create a campaign about social distance about this pandemic.

\section{Authors' Contributions}

MIH and AASS had the original idea for this study. MRH and SK helped in data collection and data entry. IH, MIH, and AASS analyzed the statistical analysis. MAZ and MIH helped to write the manuscript. MIHM, MIHN, and AT helped in reviewing and editing. All authors read and approved the final manuscript.

\section{Conflict of Interest Disclosures}

The author declares no conflict of interest.

\section{Ethical Approval}

This study did not require ethics committee authorization.

\section{Funding/Support}

This study did not receive any financial support.

\section{Acknowledgments}

We want to thank the Institute of Epidemiology, Disease Control, and Research (IEDCR) for enabling us to use the COVID-19 confirmed case and death case data of Bangladesh for our research.

\section{References}

1. Silva Júnior JVJ, Lopes TRR, de Oliveira PSB, Weiblen R, Flores EF. Issues on coronavirus disease 2019 (COVID-19) pathogenesis. Viral Immunol. 2020. doi:10.1089/vim.2020.0059.

2. Zhong NS, Zheng BJ, Li YM, et al. Epidemiology and cause of severe acute respiratory syndrome (SARS) in Guangdong, People's Republic of China, in February, 2003. Lancet. 2003;362(9393):1353-1358. doi:10.1016/s0140-6736(03)146302.

3. Cui J, Li F, Shi ZL. Origin and evolution of pathogenic coronaviruses. Nat Rev Microbiol. 2019;17(3):181-192. doi:10.1038/s41579-018-0118-9.

4. Zhou F, Yu T, Du R, et al. Clinical course and risk factors for mortality of adult inpatients with COVID-19 in Wuhan, China: a retrospective cohort study. Lancet. 2020;395(10229):10541062. doi:10.1016/s0140-6736(20)30566-3.

5. Bavel JJV, Baicker K, Boggio PS, et al. Using social and behavioural science to support COVID-19 pandemic response. Nat Hum Behav. 2020;4(5):460-471. doi:10.1038/s41562-0200884-z.

6. Corbet S, Hou Y, Hu Y, Lucey B, Oxley L. Aye Corona! The contagion effects of being named Corona during the COVID-19 pandemic. Financ Res Lett. 2021;38:101591. doi:10.1016/j. frl.2020.101591.

7. Zhu N, Zhang D, Wang W, et al. A novel coronavirus from patients with pneumonia in China, 2019. N Engl J Med. 2020;382(8):727-733. doi:10.1056/NEJMoa2001017.

8. World Health Organization. Naming the coronavirus disease (COVID-19) and the virus that causes it. 2020. https://www. who.int/emergencies/diseases/novel-coronavirus-2019/ technical-guidance/naming-the-coronavirus-disease-(covid2019)-and-the-virus-that-causes-it. Accessed December 13, 2020.

9. Worldometer. COVID-19 CORONAVIRUS PANDEMIC. 2020. https://www.worldometers.info/coronavirus/?utm campaign=CSauthorbio. Accessed December 13, 2020.

10. Pradhan D, Biswasroy P, Kumar Naik P, Ghosh G, Rath G. A review of current interventions for COVID-19 prevention. Arch Med Res. 2020;51(5):363-374. doi:10.1016/j. arcmed.2020.04.020.

11. Iacobucci G. Covid-19: UK lockdown is "crucial" to saving lives, say doctors and scientists. BMJ. 2020;368:m1204. doi:10.1136/ bmj.m1204.

12. Remuzzi A, Remuzzi G. COVID-19 and Italy: what next? Lancet. 2020;395(10231):1225-1228. doi:10.1016/s01406736(20)30627-9.

13. Pulla P. Covid-19: India imposes lockdown for 21 days and cases rise. BMJ. 2020;368:m1251. doi:10.1136/bmj.m1251.

14. Anwar S, Nasrullah M, Hosen MJ. COVID-19 and Bangladesh: challenges and how to address them. Front Public Health. 2020;8:154. doi:10.3389/fpubh.2020.00154.

15. Wang $\mathrm{D}, \mathrm{Hu} \mathrm{B}, \mathrm{Hu} \mathrm{C}$, et al. Clinical characteristics of 138 hospitalized patients with 2019 novel coronavirus-infected pneumonia in Wuhan, China. JAMA. 2020;323(11):1061-1069. doi:10.1001/jama.2020.1585.

16. Chen $\mathrm{T}, \mathrm{Wu} \mathrm{D}, \mathrm{Chen} \mathrm{H}$, et al. Clinical characteristics of 113 deceased patients with coronavirus disease 2019: retrospective study. BMJ. 2020;368:m1091. doi:10.1136/bmj.m1091.

17. Liang LL, Tseng CH, Ho HJ, Wu CY. Covid-19 mortality is negatively associated with test number and government effectiveness. Sci Rep. 2020;10(1):12567. doi:10.1038/s41598020-68862-x.

18. Roser M, Ritchie H. Coronavirus (COVID-19) Deaths Statistics and Research. 2020. https://ourworldindata.org/ covid-deaths. Accessed December 13, 2020.

19. Institute of Epidemiology, Disease Control and Research. Bangladesh COVID-19 Scenario \& Trend. 2020. https:// covid19bd.idare.io/. Accessed December 13, 2020.

20. World Health Organization. Coronavirus disease (COVID-2019) Bangladesh situation reports. 2020. https:// www.who.int/bangladesh/emergencies/coronavirus-disease(COVID-19)-update/coronavirus-disease-(covid-2019)bangladesh-situation-reports. Accessed December 13, 2020.

21. Perera W. Bangladesh government downplays COVID-19 threat as job losses mount. 2020. https://www.wsws.org/en/ 
articles/2020/03/16/bang-m16.html. Accessed December 13, 2020.

22. Mamun MA, Griffiths MD. First COVID-19 suicide case in Bangladesh due to fear of COVID-19 and xenophobia: possible suicide prevention strategies. Asian J Psychiatr. 2020;51:102073. doi:10.1016/j.ajp.2020.102073.

23. Shumway RH, Stoffer DS. Time Series Analysis and its Applications. New York: Springer-Verlag; 2006.

24. Craney TA, Surles JG. Model-dependent variance inflation factor cutoff values. Qual Eng. 2002;14(3):391-403. doi:10.1081/ qen-120001878.

25. Senaviratna NA, Cooray TM. Diagnosing multicollinearity of logistic regression model. Asian J Probab Stat. 2019;5(2):1-9. doi:10.9734/ajpas/2019/v5i230132.

26. Midi H, Sarkar SK, Rana S. Collinearity diagnostics of binary logistic regression model. J Interdiscip Math. 2010;13(3):253267. doi:10.1080/09720502.2010.10700699.

27. Myers RH. Classical and Modern Regression with Applications. Belmont, CA: Duxbury Press; 1990.

28. Menard SW. Applied logistic regression analysis. Thousand Oaks, Calif; SAGE Publications; 2002.

29. Pal R, Yadav U, Verma A, Bhadada SK. Awareness regarding COVID-19 and problems being faced by young adults with type 1 diabetes mellitus amid nationwide lockdown in India: a qualitative interview study. Prim Care Diabetes. 2021;15(1):1015. doi:10.1016/j.pcd.2020.07.001.

30. Akalu Y, Ayelign B, Molla MD. Knowledge, attitude and practice towards COVID-19 among chronic disease patients at Addis Zemen Hospital, Northwest Ethiopia. Infect Drug Resist. 2020;13:1949-1960. doi:10.2147/idr.s258736.

31. Alahdal H, Basingab F, Alotaibi R. An analytical study on the awareness, attitude and practice during the COVID-19 pandemic in Riyadh, Saudi Arabia. J Infect Public Health. 2020;13(10):1446-1452. doi:10.1016/j.jiph.2020.06.015.

32. Eslami $\mathrm{H}$, Jalili $\mathrm{M}$. The role of environmental factors to transmission of SARS-CoV-2 (COVID-19). AMB Express. 2020;10(1):92. doi:10.1186/s13568-020-01028-0.

33. Howard J, Huang A, Li Z, et al. Face Masks Against COVID-19: An Evidence Review. Preprints; 2020:1-8. doi: 10.20944/ preprints202004.0203.v1.

34. Khalatbari-Soltani S, Cumming RC, Delpierre C, KellyIrving M. Importance of collecting data on socioeconomic determinants from the early stage of the COVID-19 outbreak onwards. J Epidemiol Community Health. 2020;74(8):620-623. doi:10.1136/jech-2020-214297.

35. Zhong BL, Luo W, Li HM, et al. Knowledge, attitudes, and practices towards COVID-19 among Chinese residents during the rapid rise period of the COVID-19 outbreak: a quick online cross-sectional survey. Int J Biol Sci. 2020;16(10):1745-1752. doi:10.7150/ijbs.45221.

36. Chu DK, Akl EA, Duda S, Solo K, Yaacoub S, Schünemann HJ. Physical distancing, face masks, and eye protection to prevent person-to-person transmission of SARS-CoV-2 and COVID-19: a systematic review and meta-analysis. Lancet. 2020;395(10242):1973-1987. doi:10.1016/s01406736(20)31142-9.

37. Mahmud S. Bangladesh COVID-19 daily cases time series analysis using Facebook prophet model. SSRN Electronic Journal. 2020. doi:10.2139/ssrn.3660368.

38. Roy S, Bhunia GS, Shit PK. Spatial prediction of COVID-19 epidemic using ARIMA techniques in India. Model Earth Syst Environ. 2020:1-7. doi:10.1007/s40808-020-00890-y. 